\title{
Local development impact assessment for a high speed rail system: a Taiwan study
}

\author{
J. J. Lin ${ }^{1}$, C. M. Feng ${ }^{2}$ \& L. C. Huang ${ }^{2}$ \\ ${ }^{1}$ Graduate Institute of Urban Planning, National Taipei University, \\ Taiwan \\ ${ }^{2}$ Institute of Traffic and Transportation, National Chiao Tung University, \\ Taiwan
}

\begin{abstract}
The Taiwan high speed rail (HSR) system has been in commercial operation since January 2007. Based on the experience of previous freeway development in the area, HSR has the potential to significantly influence local development in western Taiwan. This study focused on the impact of the Taiwan HSR system on local development. Simultaneous equation modeling was applied to analyze the associations among development sectors, and is calibrated using samples of 323 villages, towns or cities in Taiwan. The calibrated model is used as a basis for analyzing and discussing the influences of improving accessibility, increasing land supply for urban development, and various other strategies related to the HSR system. This work reached the following conclusions: improving accessibility and increasing urban development land supply influences local population and employment distributions; improving connections between HSR stations and the central city benefits the development of the central city rather than HSR station area; improving connections between HSR stations and individual districts within the metropolitan area increases the HSR service area and balances development among districts, and promoting station area development projects contributes significantly to local development.

Keywords: high speed rail, local development, simultaneous equation modeling.
\end{abstract}

\section{Introduction}

The Taiwan high speed rail (HSR) system has been in commercial operation since January 2007. The travel time by land between the two end points of the 
western corridor in Taiwan, Taipei and Kaoshong has been reduced to just 90 minutes, compared to four hours before HSR service. According to the marked variation of accessibility, the distribution of population and employment may change in the future. Important questions thus include: the nature of those changes; whether the HSR benefits station areas to the detriment of non-station areas; and what should be done to disperse the benefits of HSR among a larger number of districts and to balance local development among districts. The answers to these questions are important not only for regional and local planning in Taiwan but also for assessing HSR projects in other regions which are currently planning or considering HSR projects.

Based on European and Japanese experiences, HSR systems have had an impact on two scales. Regarding the regional scale, Blum et al. [1] found that HSR has a positive effect on connecting regions, integrating regional development and eliminating regional discrepancies in development. Sasaki et al. [2] concluded that the Shinkansen was a catalyst for regional development. Specifically, the Shinkansen itself did not balance regional development unless comprehensive planning was undertaken to ensure that such a balance was achieved. Regarding the local aspect, Vickerman [3] observed European experiences and argued that HSR increased development distinctions between station and non-station areas. Nakamura and Ueda [4] found that areas with convenient connections with Shinkansen stations experienced significant population growth following the establishment of the Shinkansen. The above studies only considered the improvement in accessibility associated with the development of the HSR. However, the Taiwan HSR system includes not only a new high-speed travel system but also the station area development projects (SADPs). The influence of HSR and SADP must be considered simultaneously in the case of Taiwan.

Furthermore, most previous studies argued that HSR re-distributed development potential to HSR station areas, or to areas with good connections with HSR stations, from other areas. This trend appears harmful to the objective of spatially balanced development. Aggregate economic growth in Taiwan has been impressive during the past 40 years, but regional development has been extremely imbalanced. For example, the Northern Region comprises less than a quarter of the area of Taiwan, but accounts for over $40 \%$ of the population and nearly half of the jobs in Taiwan. Moreover, the average household income of residents in urban areas is almost 1.5 times that of those in rural areas. The HSR system may worsen these regional imbalances, and adequate strategies are required to guide local development to obtain a balanced situation. Some HSR impact studies were performed during the evaluation period for the Taiwan HSR project: Taiwan High Speed Rail Bureau evaluated the impacts on macroeconomy and regional development [5, 6], and Chou [7] explored the impacts on employment in metropolitan areas. None of these studies considered the local scale impact. Feng and Lin [8] forecasted the local development impact of numerous transportation projects using an integration approach, in which freeway, mass rapid transit and HSR were considered simultaneously and the effects of HSR could not be distinguished clearly. Therefore, HSR impact needs 
to be distinguished on a local scale to provide sufficient information for local development planning.

This study developed a local development model via simultaneous equation modeling to assess the impacts of changing accessibility and urban development land supply on local population and employment. The developed model was applied to forecast the impacts of the Taiwan HSR system on the Taichung metropolitan area via a with-and-without comparison approach under various scenarios. The rest of this paper is organized as follows: Section 2 describes the specification of local development model and the model calibration using a sample comprising 323 villages, towns or cities in Taiwan. Next, Section 3 forecasts the impacts of local population and employment under various scenarios. Finally, conclusions and recommendations are presented in Section 4.

\section{Modeling local development}

The local development model (LDM) denotes a system, which simulates the quantitative associations among socio-economic sectors within a specific area. Four sectors were chosen to describe local development: population, employment, transportation and land use. The population sector is measured by "local population as a proportion of the total population of Taiwan" to describe the change of distribution rather than total volume, which is primarily determined by development trends and is not significantly related to HSR. Similar to population, the employment sector is measured using "local employees as a proportion of total employees of secondary and tertiary industries in Taiwan. The transportation sector is measured by accessibility index, as follows:

$$
t_{i j}=\sum_{v \in V} f_{i j}^{v} \cdot t_{i j}^{v} ; \quad A_{i j}=P_{j} / e^{\beta \times t_{i j}} ; \quad A_{i}=\sum_{j \in R, j \neq i} A_{i j}
$$

where $t_{i j}$ denotes weighted average travel time from zone $i$ to zone $j, f_{i j}^{v}$ represents modal split of mode $v$ from zone $i$ to zone $j, t_{i j}^{v}$ is travel time of mode $v$ from zone $i$ to zone $j, V$ denotes the set of available modes, $A_{i j}$ represents the accessibility from zone $i$ to zone $j, \beta$ is a friction parameter, $P_{j}$ denotes local population in zone $j$ as a proportion of the total population of Taiwan, $A_{i}$ represents the accessibility of zone $i$, and $R$ is the set of zones. The first part of eqn. (1) measures the weighted average travel time between two zones considering all the available modes (railway, highway and airway for model calibration; HSR is added for forecast). The second part of eqn. (1) expresses accessibility between two zones via gravity function, and the last part of eqn. (1) aggregates accessibility for a specific zone $(i)$. The travel time of a specific mode includes line-haul time, transfer time and waiting time. Meanwhile, the land use sector is measured using four variables: area of residential zone, commercial zone, industrial zone or neighborhood facility, as a proportion of total residential zone, commercial zone, industrial zone or neighborhood facility in Taiwan. 
Based on the above variables, the hypothetical path diagram is illustrated in fig. 1 , and the model is specified in the form of a simultaneous equation model, as follows:

$$
\begin{aligned}
P_{i, t}=c_{11} \cdot & P_{i, t-1}+c_{21} \cdot\left(A_{i, t-1}\right)^{2}+c_{31} \cdot E 2_{i, t}+c_{41} \cdot E 3_{i, t}+c_{51} \cdot R A_{i, t-1}+c_{61} \cdot\left(P A_{i, t-1}\right)^{2} \\
E 2_{i, t} & =c_{12} \cdot E 2_{i, t-1}+c_{22} \cdot\left(A_{i, t-1}\right)^{2}+c_{32} \cdot P_{i, t}+c_{42} \cdot E 3_{i, t-1}+c_{52} \cdot I A_{i, t-1} \\
E 3_{i, t} & =c_{13} \cdot E 3_{i, t-1}+c_{23} \cdot\left(A_{i, t-1}\right)^{2}+c_{33} \cdot P_{i, t}+c_{43} \cdot E 2_{i, t-1}+c_{53} \cdot B A_{i, t-1}
\end{aligned}
$$

where the notations are defined in fig. 1. Both $i$ and $j$ denote zones and $t$ represents time frame. The determinations of the forms of independent variables are explained later.

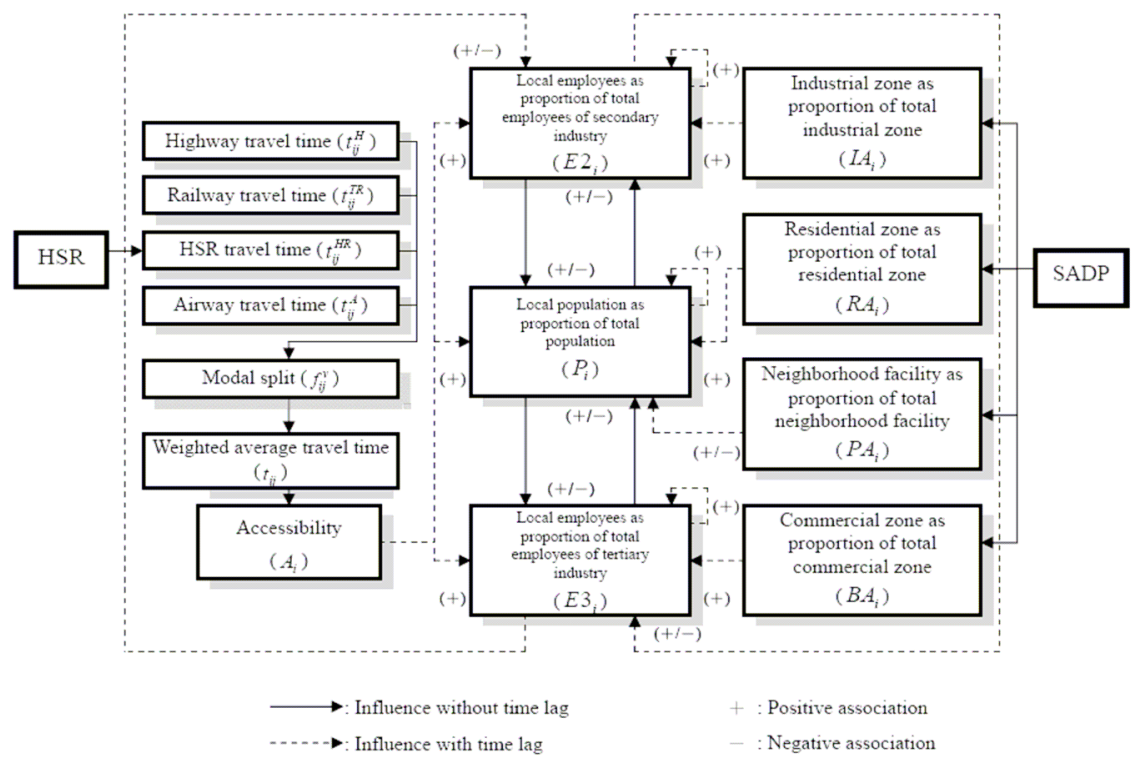

Figure 1: Hypothetical path diagram of local development.

The following factors are supposed to influence local population at time $t$ : (1) population at time $t-1$ is positively associated with population in time $t$ owing to development trends; (2) accessibility generally attracts people moving from other areas, and this attraction effect is performed with time lag; (3) residential zone increases residents with time lag; (4) neighborhood facility has two effects on population: a positive effect caused by improving living circumstance, and a negative effect caused by squeezing residential activity owing to land occupation; and (5) employment has two effects on population: one is a positive influence caused by family support, and the other one is a negative influence resulting from squeezing residential activity for the reasons of land occupation and incompatible circumstances.

Local employment in time $t$ might be influenced by the following factors: (1) employment in time $t-1$ is positively associated with employment in time $t$ owing to development trends and agglomeration economies; (2) accessibility 
attracts enterprises, but this attraction effect is only felt following a time lag; (3) increasing commercial and industrial areas induce employees with a time lag; and (4) population positively influences employment owing to labor supply and product/service demand, but population also negatively influences employment owing to land occupation and circumstance incompatibility.

Land use and transportation sectors are both exogenous in the model. A zoning system controls the land availability for urban development and is related to public policy or development planning. The SADP in the Taiwan HSR system will revise zoning in station areas and directly influence the local supply of residential zone, commercial zone, industrial zone and neighborhood facilities. Accessibility is determined by the travel time of available modes, which is related to transportation infrastructures. The travel service in the Taiwanese HSR system changes the available modes and directly influences local accessibility.

The impact of HSR system on local development can be theoretically deduced from fig. 1 and eqns. (2), (3) and (4). The travel service provided by HSR indirectly influences population via two paths: HSR-accessibilitypopulation and HSR-accessibility employment (both secondary and tertiary industries)-population. The effect of former path is generally positive, and the effect of the latter path cannot be verified before being empirically proved. Moreover, HSR station area development projects indirectly influences population via two paths: one is SADP-residential zone (or neighborhood facility)-population with positive effect, the other one is SADP-industrial (or commercial) zone-employment of secondary (or tertiary) industry-population.

A total of 323 villages, towns or cities in Taiwan were used as samples for calibrating fig. 1. Two major cities, Taipei and Kaohsiung, were treated as unique areas and excluded from the sample. Records on population, employment and travel time for various modes were derived from the Ministry of Transportation and Communication (MOTC): highway and railway travel time was obtained from the Institute of Transportation of the MOTC, and airway travel time was sourced from the Civil Aeronautics Administration of the MOTC. Data on land use zoning and neighborhood facility were obtained from the Department of Land Administration in the Ministry of the Interior. According to the time frame of the available data, this study used five years as the time lag for the model in fig. 1. In eqns. (2), (3) and (4), the years with independent variables versus dependent variables are 1996 and 2001 respectively.

The forms of the independent variables in eqns. (2), (3) and (4) were determined using the highest correlation coefficients with independent variables via a trial-and-error approach. Besides accessibility and neighborhood facility, which used square values, other independent variables used original values. The $\beta$ value equaled 2 via the above approach.

The two-stage least squares (2SLS) approach was applied for model calibration. The independent variables with insignificant coefficients or which present serious collinearity with other variables were removed from the model. The Weighted least squares (WLS) method was used during the second stage of 
2SLS approach to maintain the homoscedasticity assumption of the error term. The assumption of normal error term distribution was verified by KolmogorovSmirnov testing. After numerous calibrations and revisions, the empirical path diagram is illustrated in fig. 2 , and the calibrated equations are as follows:

$$
\begin{gathered}
P_{i, t}=0.062\left(A_{i, t-1}\right)^{2}+0.158 E 2_{i, t}+0.654 E 3_{i, t}+0.004 R A_{i, t-1}-0.082\left(P A_{i, t-1}\right)^{2} \\
\left(A d j . R^{2}=0.998, F=32816.217\right) \\
E 2_{i, t}=1.372 P_{i, t}-0.510 E 3_{i, t-1}+0.042 I A_{i, t-1}-0.000855 \\
\left(A d j . R^{2}=0.884, F=615.356\right) \\
E 3_{i, t}=1.009 P_{i, t}-0.135 E 2_{i, t-1}+0.087 B A_{i, t-1}-0.000639 \\
\left(\text { Adj. } R^{2}=0.974, F=2948.671\right)
\end{gathered}
$$

Huang [9] presents the detailed calibration process and results. All of the coefficients are significant at $\alpha=0.005$.

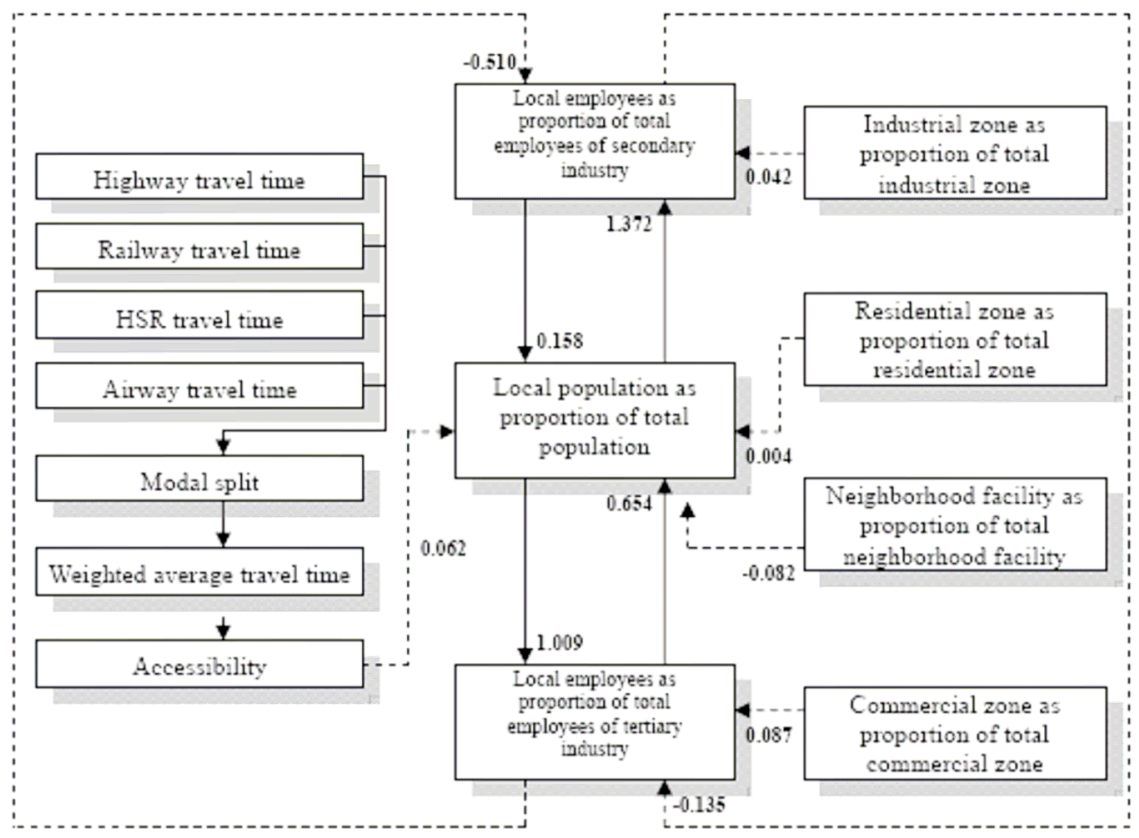

Figure 2: Empirical path diagram of local development.

The following findings can be obtained based on the calibrated model. First, local population is positively influenced by accessibility, employment of secondary and tertiary industries and residential zone. Meanwhile, neighborhood facility negatively influences local population, meaning that the negative effect of land occupation exceeds the positive effect of circumstance attraction. Second, number employed in secondary industry is positively influenced by population and industrial zone. Number employed in tertiary industry negatively influences number employed in secondary industry, meaning that the negative effect of land occupation exceeds the positive effect of attraction. Finally, the number locally employed in tertiary industry is positively influenced by 
population and commercial zone. Number employed in secondary industry negatively influences employment of tertiary industry, meaning that the negative effect of land occupation exceeds the positive influence of attraction. Figure 2 illustrates that accessibility influences local employment indirectly via local population.

\section{Forecast}

Taichung HSR station is located at U-Ryh Village, which is far from the centre of the metropolis and has poor transportation links to the centre. Doubts thus exist regarding whether Taichung station will enable Taichung to fully benefits from the benefits of the HSR system. Simulating the impacts of alternative land use zoning on local development is helpful in creating the development plan.

This study forecasted the impacts of alternative strategies (including access system and land use zoning) of Taichung HSR station on local development in the metropolis. The Taichung metropolitan area is the focus of development for the Central Taiwan. It covers 29 Villages, Towns, Cities or Districts, as shown in fig. 3, where eight Districts in Taichung City comprise the central business area of the metropolis. The Taichung metropolitan area contained approximately 2.5 million people living in the land area of 2.2 thousand $\mathrm{km}^{2}$. Taichung grew rapidly during the past decade compared to the other metropolises in Taiwan. According to the visible potential, HSR is expected to influence metropolitan development, especially in activity distribution among districts. The forecast was performed from the base year of 2001 to the target year of 2021 using a four stage simulation via eqns. (5), (6) and (7). Each stage comprises five years to match the time lag of the calibrated model.

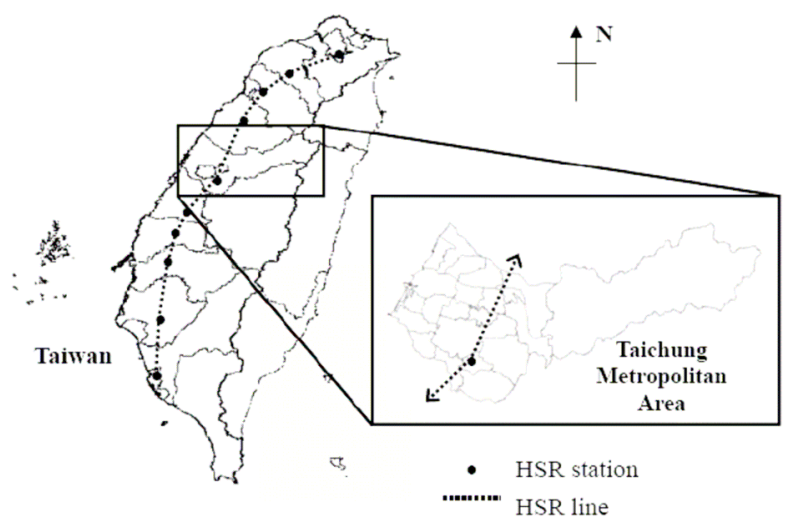

Figure 3: $\quad$ Taichung metropolitan area.

Three major assumptions were made during the simulated years: First, the HSR system is assumed to be the only major change capable of influencing local development. Second, the associations of the path diagram in fig. 2 are assumed to remain constant. Third, other HSR stations besides Taichung station are 
assumed not to significantly influence the development of Taichung metropolis. The input data for the base year is assumed to be from the same source as the data used for model calibration, while the input data which requires forecasting is assumed to come from various sources: HSR travel time is estimated by the Taiwan High Speed Rail Company, and mode split is forecast by the Institute of Transportation [10]. Finally, the base situation of land use zoning for the SADP of Taichung station was assumed to be the average split of land use zoning of other demonstrated SADPs from the Council for Economic Planning and Development.

Three possible strategies are considered. The first strategy involves improving the connection between HSR station and the central city. Most stations in the Taiwan HSR system are located in rural area and thus require improved connections with central city areas. Success in implementing this strategy can be measured by the reduction of travel time between stations and central city areas, and two situations are considered, namely $0 \%$ and $30 \%$ reductions in existing travel time between the HSR station and Taichung City. The second strategy is to improve the access system between HSR stations and the various districts within the metropolitan area. Since the HSR system has long distances between stations, good access systems for HSR stations is important in enlarging the service area of HSR and minimizing accessibility-difference between station areas and non-station areas. Once again, this strategy can be measured by the reduction of travel time, and three situations are considered: $0 \%, 30 \%$ and $50 \%$ reductions of the existing travel time between the Taichung HSR station and individual districts in the metropolitan area. Finally, the third strategy is to promote SADP around stations. Because Taichung station is located in a rural area, inducing more urban activities around the station is beneficial to the HSR and the urban activity itself. This strategy can be measured via the planned scale of area, and three situations are considered: $0 \%, 50 \%$ and $100 \%$ of base situation.

Combining the above situations, 18 scenarios were analyzed for forecasting as shown in table 1. For example, scenario 5 involves the following situations: $0 \%$ reduction of travel time between HSR station and Taichung City, 70\% reduction of travel time between the HSR station and individual districts in the metropolitan area and $50 \%$ of SADP base situation.

Huang [9] presents the forecast results for all scenarios. This study used four indexes to assess the performance of 18 scenarios: index 1 expresses the maximum value of the population or employment variable among all districts; index 2 indicates the minimum value of the population or employment variable among all districts; index 3 is the difference between the maximum and minimum values; and index 4 is the ratio of the number of districts, which are displaying negative changes in population or employment variable, to the total number of districts in the metropolitan area. The increase of indexes 1 or 2 increases the performance of promoting local development, while the increase of indexes 3 or 4 reduces the effectiveness of balancing development among districts.

Figure 4 compares the performance of 18 scenarios. For index 1, scenarios 4 to 9 and scenarios 16 to 18 outperform other scenarios. All of these scenarios 
Table 1: $\quad$ Strategy scenarios.

\begin{tabular}{|l|c|c|c|c|}
\hline \multicolumn{3}{|c|}{ Strategy 1: $0 \% / 30 \%$ reduction of travel time between HSR station and Taichung City } \\
\hline \multicolumn{2}{|l|}{ Strategy 2 } & \multicolumn{3}{|c|}{$\begin{array}{c}\text { Reduction of travel time between HSR station and } \\
\text { individual districts in metropolitan area }\end{array}$} \\
\cline { 3 - 5 } Strategy 3 & $100 \%$ & $70 \%$ & $50 \%$ \\
\hline $\begin{array}{l}\% \text { of base situation } \\
\text { of SADP for } \\
\text { Taichung station }\end{array}$ & $0 \%$ & Scenario $1 / 10$ & Scenario 2/11 & Scenario 3/12 \\
\cline { 2 - 5 } & $50 \%$ & Scenario 4/13 & Scenario 5/14 & Scenario 6/15 \\
\cline { 2 - 5 } & $100 \%$ & Scenario 7/16 & Scenario 8/17 & Scenario 9/18 \\
\hline
\end{tabular}
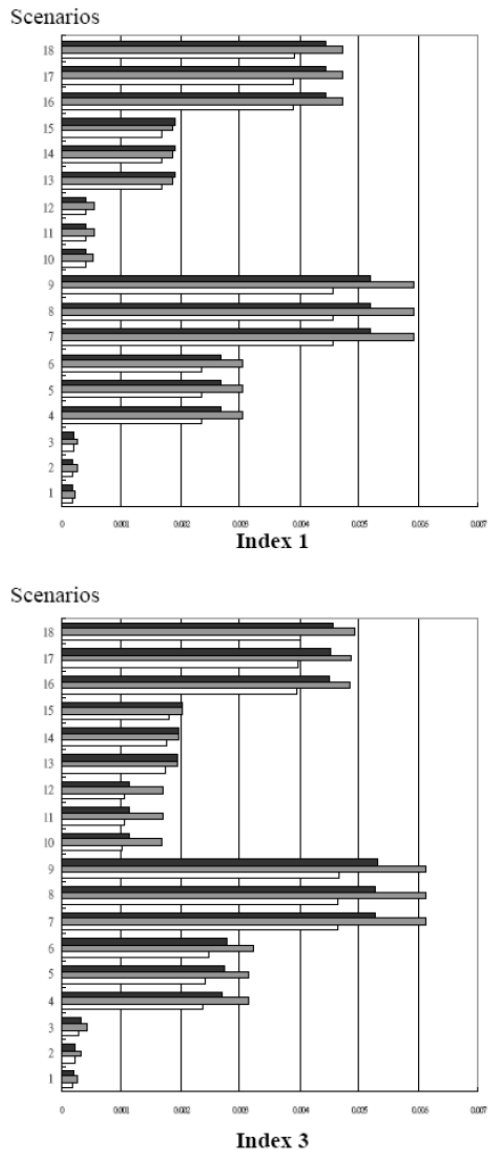

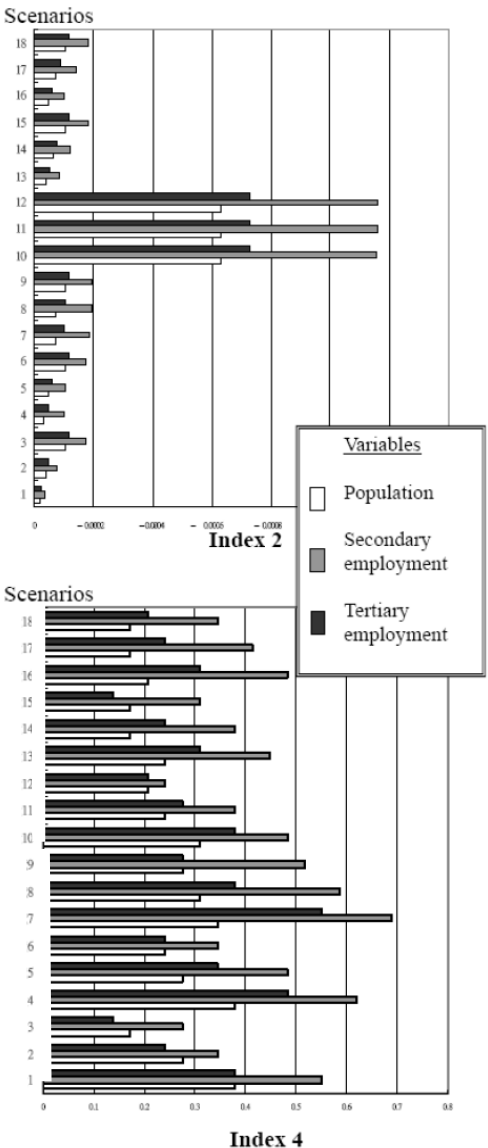

Figure 4: $\quad$ Performance comparisons of 18 scenarios.

promote SADP around the station and imply that land supply for urban development significantly and positively influences local development. For index 2, scenarios 10 to 12 perform worse than the other scenarios. In these three scenarios, the connections between HSR stations and the central city areas are improved, but SADP around stations is not promoted. Accordingly, HSR 
stations cannot stimulate local development without land development planning. For index 3, scenarios 1 to 9 and scenarios 10 to 18 display a similar cycle, meaning that the balance of development among districts worsens with increasing SADP scale and the improvement of connections between HSR stations and the central city. For index 4, scenarios 3 and 12 outperform the other scenarios. These two scenarios both significantly improve the connection between HSR station and individual districts, thus enlarging the service area of the HSR system and benefiting more districts in terms of accessibility.

The above discussion yielded the following findings: First, without any other actions, the travel service provided by HSR will promote local development within a limited service area and cause a relative decline in local development outside the service area. Second, improving the connections between HSR stations and central city negatively influences the development of station area and benefits the development of the central city. The reason is that the above connection leads to an insignificant difference in accessibility between station areas and the central city while simultaneously the central city offers other attractions that are generally better than those offered by the HSR station area. Third, improving the connections between HSR stations and individual districts in metropolitan area enlarges the HSR service area and benefits the development of a larger number of districts. Fourth, scale of SADP is positively related to local development in station areas. Finally, SADP significantly promotes local development, while improving connections between HSR stations and individual districts helps to balance development among districts and acts as a catalyst in promoting local development.

\section{Conclusions}

This study applied simultaneous equation modeling and 323 samples from Taiwan to develop a local development model. The calibrated model demonstrates that improving accessibility and increasing land supply for urban development, which will be the effect of the Taiwan HSR system, significantly influences local population and employment development.

The calibrated model was used to forecast the influence of the Taiwan HSR system on local development in the Taichung metropolitan area under various scenarios. The forecast results show that HSR will positively influence districts within its service area. This finding supports the conclusions of Vickerman [3]. Furthermore, SADP influences local development more than accessibility improvement does. Transportation infrastructure thus is necessary, rather than sufficient, for local development. This argument resembles that of Sasaki et al. $[2]$.

The performance comparisons of 18 scenarios revealed that improving connections between HSR stations and central city benefits the development of the central city rather than the HSR station area. Furthermore, improving connections between HSR stations and individual districts in metropolitan areas will enlarge the HSR service area and balance development among districts. Promoting SADP contributes significantly to local development. 
As a new infrastructure in Taiwan, HSR is expected to significantly influence local, regional and national development. However, current studies on the impact of HSR in Taiwan remain insufficient for strategy design or policy making. This study recommends two directions for further exploration. First, this study forecast the local development impacts of an HSR system. Thus, to accumulate further information, empirical evidence studied using a before-andafter comparison approach will be required in the future. Next, various HSR systems exist in Asia and Europe, each with different social-economic contexts. The differences among the impacts of different HSR systems deserve comparison, which is helpful not only for developing theories regarding land use-transportation interaction but also for supplying information to HSR projects that are currently being evaluated, planned and reviewed.

\section{References}

[1] Blum, U., Haynes, K. E. \& Karlsson, C., Introduction to the special issue: the regional and urban effects of high-speed trains. Annals of Regional Science, 31, pp. 1-20, 1997.

[2] Sasaki, K., Ohashi, T. \& Ando, A., High-speed rail transit impact on region system: does the Shinkansen contribute to dispersion. Annals of Regional Science, 31, pp. 77-98, 1997.

[3] Vickerman, R., High-speed rail in Europe: experience and issues for future development. Annals of Regional Science, 31, pp. 21-38, 1997.

[4] Nakamura, H. \& Ueda, T, The impacts of Shinkansin on regional development. Proc. of the $3^{\text {rd }}$ World Conf. on Transport Research, Yokohoma, pp. 95-109, 1989.

[5] Bureau of Taiwan High Speed Rail, Impact Study of High Speed Rail Project on Macro Economy, Report prepared by the Far East Consults on Economic Study, Inc, 1993. (In Chinese)

[6] Bureau of Taiwan High Speed Rail, Impact Study of High Speed Rail on Regional Development, Report prepared by the Chinese Regional Science Association-Taiwan, 1997. (In Chinese)

[7] Chou, C. S., Impact study of high speed rail on tertiary employment in Taipei metropolitan area. Transportation Planning Journal, 20, pp. 149 168, 1991. (In Chinese)

[8] Feng, C. M. and Lin, J. J., Impact study of major infrastructures on regional development: a case study of Northern Taiwan Region. Transportation Planning Journal, 21, pp. 367-400, 1992. (In Chinese)

[9] Huang, L. C., The Impact Analysis of Taiwan High Speed Rail System on Local Development, Master degree thesis submitted to Institute of Traffic and Transportation, National Chiao Tung University, 2004. (In Chinese)

[10] Institute of Transportation, The Third Taiwan Area Comprehensive Transportation Systems Planning Study-Forecast and Analysis of Systems Demand and Supply, Report prepared by THI Consults, Inc, 1999. (In Chinese) 